\title{
SUBROGACIÓN CONVENCIONAL Y STJUE 11.7.2018 (SOMOZA HERMO): ENTRE APLICAR EL ARTÍCULO 44.3 ET O TRANSITAR EL -HASTA AHORA- INERTE CAMINO DEL CONVENIO COLECTIVO COMO NORMA DE TRANSPOSICIÓN
}

\author{
Manuel Luque Parra \\ Catedrático de Derecho del Trabajo y de la Seguridad Social \\ Universidad Pompeu Fabra
}

\begin{abstract}
El presente estudio analiza la cuestión relativa a los efectos laborales de la subrogación convencional a raíz de la reciente sentencia del Tribunal de Justicia de la Unión Europea de 11 de julio de 2018, asunto Somoza Hermo. El trabajo concluye que la sentencia significa una necesaria revisión de la doctrina del Tribunal Supremo según la cual, si bien la subrogación convencional es un supuesto amparado por la Directiva, el convenio colectivo configura válidamente el supuesto de hecho y sus consecuencias jurídicas.
\end{abstract}

The paper analyses the labor effects of conventional subrogation in the context of the decision of European Court of Justice of July 11 ${ }^{\text {th }}$, 2018, case Somoza Hermo. The paper concludes that the decision means a necessary revision of the case law of the Supreme Court according to which, although conventional subrogation is covered by the Directive, the collective agreement validly configures the factual assumption and its legal effects.

Title: Conventional subrogation and the decision ECJ July 11 ${ }^{\text {th }}$, 2018 (Somoza Hermo): between applying article 44.3 Spanish Worker's Statute or transit the -until nowunexplored path of collective agreements as transposition norms.

Palabras clave: sucesión de empresa, subrogación convencional, convenio colectivo, norma transposición, Directiva 2001/23/CE

Keywords: transfer of undertakings, conventional subrogation, collective agreement, transposition norms, Directive 2001/23/CE

IUSLabor 2/2018, ISSN 1699-2938, p. 234-243

DOI: 10.31009/IUSLabor.2018.i02.08 


\section{Sumario}

1. Introducción

2. Hechos más relevantes y posicionamiento del TJUE

3. Valoración jurídica 


\section{Introducción}

Nada más y nada menos que 17 años contemplan la regulación estatutaria vigente en materia de sucesión de empresa y, sin embargo, estamos lejos de tener claros algunos aspectos básicos referidos tanto a las consecuencias jurídicas del proceso sucesorio, como a la propia delimitación de las situaciones que dan lugar a dichas consecuencias y la adecuación de todo ello a derecho comunitario.

En efecto, el redactado actual del artículo 44 del Estatuto de los Trabajadores (en adelante, ET) sobre sucesión de empresa tiene su origen en la Ley 12/2001, de 9 de julio (BOE de 10 de julio), que incorporó a nuestro ordenamiento jurídico las reformas contenidas en la Directiva 2001/23/CE, de 12 de marzo de 2001, del Consejo, "sobre la aproximación de las legislaciones de los Estados miembros relativas al mantenimiento de los derechos de los trabajadores en caso de traspasos de empresas, de centros de actividad o de partes de empresas o centros de actividad" (en adelante, Directiva 2001/23/CE o simplemente la Directiva). Directiva que derogó y refundió las Directivas anteriores 77/187/CEE (LCEur 1977/67) y 98/50/ CE (LCEur 1998/2285). ${ }^{1}$

\footnotetext{
${ }^{1}$ En palabras del profesor MARTÍN VALVERDE en la STS UD 5 de marzo de 2013 (RJ 2013/3649): "[l]a redacción actual (del año 2001) del artículo 44ET tiene su principal razón de ser en los cambios normativos derivados de las Directivas europeas en esta materia. Estas disposiciones de Derecho comunitario han sido tres; la primera es la Directiva 77/187 CEE (LCEur 1977,67), la segunda la Directiva 98/50 CE (LCEur 1998, 2285), y la tercera actualmente en vigor la Directiva CE 2001/23 (LCEur 2001, 1026). Tales cambios normativos en el Derecho comunitario, determinantes a su vez de la modificación del artículo 44ET acaecida en julio de 2001, se han debido en buena medida a la evolución de la jurisprudencia del Tribunal de Justicia de la Unión Europea, contenida en una multitud de sentencias procedentes algunas de ellas de cuestiones prejudiciales planteadas por tribunales de justicia españoles. La jurisprudencia de esta Sala de lo Social del Tribunal Supremo establecida para la anterior redacción del artículo 44ET había mantenido que para que existiera transmisión de empresa era necesario que se hubiera producido una transmisión al cesionario de los elementos patrimoniales que configuran la infraestructura u organización empresarial básica de la explotación. Pero esta doctrina jurisprudencial ha sido modificada en parte, a raíz de la entrada en vigor de la nueva redacción del repetidamente citado artículo 44ET, para adaptarse a la ampliación del supuesto de echo legal que dicha redacción ha traído consigo. Exponentes recientes de esta línea jurisprudencial, cuyo arranque se remonta a varias sentencias del año 2004, son entre otras las sentencias de 28 de abril de 2009 (RJ 2009,2997) (RCUD 4614/2007) y de 7 de diciembre de 2011 (RJ 2012,106) (RCUD 4665/2010), en las que se citan abundantes precedentes tanto de la jurisprudencia comunitaria como de nuestra jurisprudencia."

Sobre los antecedentes del precepto vigente, entre otros, véase a VALDES DAL-RÉ, Fernando, La transmisión de empresas y las relaciones laborales. Un estudio comparado de los ordenamientos comunitario y nacional, Ministerio de Trabajo y de la Seguridad Social, Madrid, 2001, p. 11-33. También a MORENo GENÉ, Josep, El nuevo régimen jurídico-laboral de la sucesión de empresas, Tirant lo Blanch, Valencia, 2003, p. 11-24.

Sobre la evolución de la doctrina judicial comunitaria en los últimos años, véase: MARTínEz SALDAÑA, David (Coord.), "La decisiva influencia del derecho comunitario en la sucesión de empresas: la Directiva
} 
No obstante, a pesar de los años transcurridos, no son pocas las cuestiones controvertidas que aún quedan por resolver, referentes tanto al supuesto de hecho como a la consecuencia jurídica del fenómeno sucesorio. Así, a modo de ejemplo:

- Sobre la consecuencia jurídica, la correcta o incorrecta transposición en nuestro ordenamiento jurídico del "año de espera" que impone el párrafo segundo del artículo 3 de la Directiva referido a la limitación del período de mantenimiento de las condiciones de trabajo establecidas en convenio colectivo.

- Sobre la determinación del convenio colectivo aplicable -y, en concreto, la cláusula de subrogación convencional prevista- en supuestos de empresas multiservicios y en los que pueda ponerse en duda la doctrina de unidad de empresa y unidad de convenio, como ya ha sucedido en el ámbito de los centros especiales de empleo. ${ }^{2}$

- O, finalmente, sobre la cuestión que es objeto de este análisis, como es la adecuación a derecho comunitario de la habitual configuración por parte de los convenios colectivos del supuesto de subrogación en actividades que se fundamentan en mano de obra, exonerándose de responsabilidad a la empresa entrante por deudas salariales contraídas por la empresa saliente antes de la transmisión.

Pues bien, a raíz de dos cuestiones prejudiciales planteadas por el TSJ de Galicia, mediante auto de 30 de diciembre de 2016, recibido en el Tribunal de Justicia el 6 de febrero de 2017, hace pocos días hemos conocido la opinión del TJUE con relación a si el supuesto de subrogación convencional entra dentro del ámbito de aplicación de la Directiva y sobre la adecuación a derecho comunitario de la antedicha cláusula de exoneración de responsabilidad de la empresa entrante.

\section{Hechos más relevantes y posicionamiento del TJUE}

Los hechos más significativos del caso de autos son los siguientes:

- La empresa ESABE VIGILANCIA (“ESABE”) fue la adjudicataria del servicio de vigilancia de un Museo en Santiago de Compostela hasta octubre de 2012, momento que en que dicho servicio se adjudicó a VIGILANCIA INTEGRADA, S.A. ("VINSA").

2001/23/CE y la jurisprudencia del Tribunal de Justicia de la Unión Europea", La sucesión de empresa, Valladolid, Lex Nova, 2016. p. 1-25.

${ }^{2}$ El centro de empleo como empresa saliente: STS UD 22.4.2013 (RJ 2013 385 ). El centro de empleo como empresa entrante (criterio funcional): STS UD 21.10.2013. 
- El Sr. Somoza, que había trabajado como vigilante para ESABE, pasó a estar contratado por VINSA, a quien reclamó las diferencias salariales y de prestaciones sociales complementarias devengadas durante los años 2010 a 2012.

- Ambas empresas se negaron al pago de la cantidad. VINSA entendió que no se trataba de una sucesión de empresas con base en el artículo $44 \mathrm{ET}$, sino que resultaba de aplicación el artículo 14 del Convenio colectivo de las empresas de seguridad, que obliga a la nueva adjudicataria a subrogarse en los derechos y obligaciones de la sociedad cedente derivados de los contratos de trabajo a partir de la fecha de adjudicación, exonerándola de las deudas generadas con anterioridad a la misma.

Ante tales hechos:

- El juzgado de instancia estimó parcialmente la demanda y, basándose en el artículo 44.3 ET, condenó a ESABE y VINSA al pago solidario de las deudas.

- Recurrida la sentencia de instancia en suplicación, el TSJ de Galicia decidió suspender el procedimiento y elevar una doble cuestión prejudicial al TJUE.

En primer lugar, se pregunta al TJUE si la Directiva 2001/23 (concretamente el artículo 1, apartado 1) es aplicable al caso.

El Tribunal resuelve que sí aplica la Directiva al supuesto en que un arrendatario de servicios ha resuelto un contrato de prestación de servicios de vigilancia de instalaciones y, a efectos de la ejecución de esta prestación, ha celebrado un nuevo contrato con otra empresa que se hace cargo, en virtud de un convenio colectivo, de una parte esencial, en términos de número y de competencias, del personal que la primera empresa destinaba a la ejecución del servicio.

En este sentido, el TJUE recuerda que en los sectores en los que la actividad descansa fundamentalmente en la mano de obra, un conjunto de trabajadores que ejerce de forma duradera una actividad común puede constituir una "entidad económica" y la misma puede mantener su identidad aun después de su transmisión cuando el nuevo empresario continúe con la actividad y se haga cargo de una parte esencial del personal. Afirma también que una actividad de vigilancia de un museo, que no exige el uso de materiales específicos, puede considerarse una actividad que descansa fundamentalmente en mano de obra y, por consiguiente, a falta de otros factores de producción, constituir una unidad económica. 
En relación con la segunda cuestión, esto es, sobre si debe interpretarse que el artículo 3, apartado 1, párrafo segundo de la Directiva 2001/23, se opone a que, en virtud de un convenio colectivo, se excluya la responsabilidad solidaria entre cedente y cesionario, el TJUE se declara incompetente para resolverla, siendo una cuestión que compete a los Tribunales nacionales resolver.

\section{Valoración jurídica}

Éramos muchos los que estábamos expectantes desde hace muchos meses a lo que el TJUE pudiera decir, pues a nadie se le escapa que:

1. La mayoría de los convenios colectivos sectoriales en actividades fundamentadas básicamente en la mano de obra configuran el supuesto de subrogación convencional (1) delimitando subjetivamente los trabajadores a los que se aplica (normalmente, los que tengan una antigüedad de 6 a 9 meses) y previendo que la empresa entrante no asume las deudas que la saliente tuviese con dichos trabajadores con anterioridad a la consumación del supuesto sucesorio ${ }^{3}$.

2. El criterio consolidado del Tribunal Supremo en más de 40 sentencias dictadas desde la "inicial o primaria" que en Sala General dictó en 2016, en las que concluye de manera indubitada que cuando la subrogación se produce en virtud del mandato contenido en el convenio colectivo aplicable, no se ha producido una sucesión de empresa por sucesión de plantillas que produzca los efectos jurídicos del artículo 44 ET y que, por tanto, es el convenio colectivo el que configura el supuesto de hecho y la consecuencia jurídica, validando tales cláusulas de exoneración de responsabilidad.

Siendo así, una sentencia del TJUE que considerase que dicha "regulación tipo" de la subrogación convencional en España es contraria a derecho comunitario, debiendo ser aplicable lo dispuesto en el artículo 44 ET, tendría no sólo un impacto en la doctrina casacional sino, sobre todo, en las "reglas del juego" de las que se han dotado un número de sectores productivos, socioeconómicamente hablando -nada desdeñable.

Pues bien, como decíamos, el TJUE en tres muy breves párrafos ha optado por declararse incompetente para conocer de un conflicto que considera es de relación entre fuentes de derecho interno: ley-convenio colectivo.

\footnotetext{
${ }^{3}$ Sobre ambas cuestiones, me remito a la monografía que he realizado sobre la configuración del supuesto de hecho inextenso y que será publicada antes de fin de año.
} 
Llegados a este punto, la gran pregunta es dilucidar qué pasará ahora. Primero en sede del TSJ de Galicia y, en caso de que dicho Tribunal considere que la norma aplicable es el artículo 44.3 ET, si el Tribunal Supremo mantendrá o no su contundente y diáfano posicionamiento actual.

En mi opinión sólo caben 3 opciones, a saber:

- La consideración que en dicho conflicto de fuentes debe solventarse aplicando la única norma de transposición existente hasta el momento, a excepción de los supuestos concursales, como es el artículo $44.3 \mathrm{ET}$, siendo, por tanto, poco probable que el Tribunal Supremo pueda mantener su doctrina actual. Posición mantenida por la mayoría de los amigos-expertos con los que he hablado y que ha defendido ya por escrito mi colega BELTRÁN DE HEREDIA.

- El mantenimiento de la doctrina del Tribunal Supremo, pero debiendo trabajar mucho más su configuración actual, debiendo pasar por el, hasta ahora, inerte camino del convenio colectivo como norma de transposición. Opción que me parece más que interesante a corto y medio plazo.

- La aprobación de una modificación normativa análoga a lo que ya se ha hecho con relación a la contratación en el sector público. En efecto, en el artículo 130.6 de la LCSP se dispone que "6. Sin perjuicio de la aplicación, en su caso, de lo establecido en el artículo 44 del Texto Refundido de la Ley del Estatuto de los Trabajadores, aprobado por Real Decreto Legislativo 2/2015, de 23 de octubre, el pliego de cláusulas administrativas particulares siempre contemplará la obligación del contratista de responder de los salarios impagados a los trabajadores afectados por subrogación, así como de las cotizaciones a la Seguridad social devengadas, aún en el supuesto de que se resuelva el contrato y aquellos sean subrogados por el nuevo contratista, sin que en ningún caso dicha obligación corresponda a este último. (...)”

Y es que, para abordar la problemática de la subrogación convencional, no hay que olvidar que el artículo 44 ET prevé la responsabilidad solidaria de la empresa entrante con relación a las deudas de la saliente con los trabajadores afectos a la sucesión, cuando la Directiva es más laxa, pues -recuérdese- que en su artículo 3.1 dispone que "[1]os Estados miembros podrán establecer que, después de la fecha del traspaso, el cedente y el cesionario sean responsables solidariamente de las obligaciones que tuvieran su origen, antes de la fecha del traspaso, en un contrato de trabajo o en una relación laboral existentes en la fecha del traspaso". 
En palabras del Tribunal Supremo: "[e]n concordancia con este mandato el artículo 44.3ET establece la responsabilidad solidaria de ambas empresas a las transmisiones por actos inter vivos durante tres años por obligaciones laborales nacidas con anterioridad a la transmisión y que no hubieran sido satisfechas. Se trata, pues, de una previsión específica incorporada por el legislador español que, yendo más allá del comunitario, ha establecido que en los casos de sucesión empresarial no sólo se produce la subrogación de la nueva en los derechos y obligaciones del anterior respecto los trabajadores cedidos, sino que ha mantenido la responsabilidad solidaria de ambas empresas respecto de las deudas laborales que la empresa cedente tuviera pendientes de abonar (SSTS de 15 de julio de 2003 (RJ 2003,6108), rcud. 3442/2001 y 4 de octubre de 2003 (RJ 2003,7378), rcud. 585/2003, entre otras)."

Siendo así, en mi opinión y tal y como defendí a finales de octubre en mi trabajo de investigación inédita para acceder al Cuerpo de Catedráticos de Universidad, con o sin sentencia del TJUE, la doctrina casacional es del todo incorrecta, pues es claro que la única norma de transposición del apartado 3.1 de la Directiva es el artículo 44.3 ET.

Con todo, afirmar sin mayores matizaciones que la sentencia del TJUE que comentamos significa una necesaria revisión de la doctrina casacional obvía que el Tribunal Supremo, con carácter mayoritario, ha afirmado que (1) la subrogación convencional es un supuesto amparado por la Directiva, pero que (2) el convenio colectivo configura válidamente el supuesto de hecho y la consecuencia jurídica del fenómeno que regula.

En mi opinión, como decía, independientemente de la sentencia comunitaria que se comenta, el Tribunal Supremo únicamente puede mantener su doctrina si argumenta que el convenio colectivo sectorial está jugando un rol de norma de transposición y, por tanto, siendo quién concreta las consecuencias jurídicas de los supuestos sucesorios de actividades no fundamentadas en medios materiales o inmateriales, sino en mano de obra. La configuración del convenio colectivo como norma de transposición no es nada fácil, pero es una opción normativa permitida en la doctrina comunitaria, si bien es un camino, reitero, no transitado hasta el momento en España y que, además, tiene unas reglas del juego en los países que así lo han ejercitado muy precisas. De lo contrario, con esta STJUE o sin ella, la única norma de transposición vigente es, reitero, el artículo 44.3 ET, salvo en el ámbito, ya comentado, de aplicación de la LCSP.

Así, compartimos con, entre otros autores, GARCíA MURCIA, la indudable capacidad técnica del convenio colectivo -en cuanto norma jurídica en sentido estricto- para 
desarrollar, como sucede en otros estados miembros, el rol de norma de transposición, pero para que ello sea así normalmente se exigen una serie de condiciones ${ }^{4}$, como son:

- Consenso expreso o tácito entre el Estado y los agentes sociales para que se produzca dicha transposición mediante un convenio colectivo.

- Se realice en el plazo marcado por la norma europea.

- Garantizar la aplicación homogénea y transversal de dicha transposición en todo el territorio nacional.

- Con carácter general, que sea un "acuerdo sobre materia concreta" ex artículo 83.3 ET y tener, como norma de transposición, una vigencia no limitada en el tiempo.

No obstante, lo cierto es que aunque el Tribunal Supremo en ningún momento plantea de manera directa la problemática sobre si el convenio colectivo está desarrollando en materia de subrogación convencional un rol de norma de transposición, por mucho que indirectamente lo parece estar validando, un mínimo análisis de los requisitos exigibles claramente nos hacen concluir que en ningún caso estamos ante una situación en la que sea posible afirmar que dichas cláusulas convencionales sectoriales y temporalmente limitadas y aprobadas en cualquier momento son -ni en su creación, ni en su configuración- normas de transposición de la Directiva.

En cualquier caso, incluso en el supuesto de que el convenio colectivo sea norma de transposición o de generalizarse como norma de transposición de rango legal lo dispuesto hasta ahora sólo en el ámbito de contratación en el sector público, lo único

\footnotetext{
${ }^{4}$ En opinión de GARCÍA MURCIA "nada impide que las directivas puedan transponerse por la negociación colectiva, pudiendo los Estados sustituir la intervención normativa directa, a través de la promulgación de las correspondientes disposiciones legales, reglamentarias y administrativas, por la garantía de que los propios interlocutores sociales, a petición conjunta, establezcan como pasa en otros estados miembros y dentro del plazo fijado por la norma europea las disposiciones necesarias mediante el oportuno acuerdo".

Como afirma el mismo autor, "en nuestro país esta potencialidad no ha sido aprovechada nunca, reduciendo el papel de la negociación colectiva a informar con carácter previo a la adopción de una norma".

Ciertamente, como dice el autor, dejar en manos de los interlocutores sociales una tarea de tal envergadura "entraña para el Estado la dificultad de garantizar, como se le exige, que la transposición de la Directiva ha sido completa y general, asegurando que afecta a todo el territorio y comprende todos los aspectos del resultado perseguido por la norma comunitaria. Recomendando normas estatales de carácter supletorio o acudiendo al excepcional mecanismo de la extensión del 92.2." Añadiendo que, además, "debiera hacerse por tiempo indefinido al carecer de sentido una transposición de duración determinada.", abogando por los acuerdos sobre materias concretas ex artículo 83.3 ET como mejor mecanismo convencional regulatorio.

El autor en El sistema de fuentes de la relación laboral: estudios ofrecidos al profesor Martín Valverde, Universidad de Oviedo, Oviedo, 2007, p. 173 y 174.
} 
que cabrá es disponer de lo que la Directiva declara disponible, esto es, de si la empresa entrante asume o no la posición de responsable solidario con la saliente de las deudas que esta última tuviera con los trabajadores afectos a la sucesión. Lo que no veo por ningún lado es que sean acordes a derecho comunitario las habituales delimitaciones subjetivas de dichas cláusulas sobre subrogación convencional de las que sólo se benefician los trabajadores de una determinada antigüedad (6-9 meses), pues la Directiva exige que de producirse un fenómeno amparado por la misma (como es el caso) todos, reitero, todos los trabajadores afectos a la sucesión han de mantener su relación laboral vigente con el empresario entrante. 